\title{
Swimming through the substrate: the neoichnology of Chalcides ocellatus and biogenic structures of sand-swimming vertebrates
}

\author{
Angeline M. Catena and Daniel I. Hembree
}

\begin{abstract}
Neoichnological experiments involving a species of sand-swimming skink, Chalcides ocellatus, demonstrate the diversity of biogenic structures produced by desertdwelling lizards. The skinks were placed into terrariums with ten, 1-cm-thick layers of fine-, medium-, or coarse-grained sand for periods of 7 to 14 days. Sediment moisture content was held constant at either $0 \%$ or $20 \%$. The sand skinks exhibited locomotion, escape, and resting behaviors. They burrowed to a maximum depth of $4.2 \mathrm{~cm}$ with most activity restricted to the upper $2 \mathrm{~cm}$ of the sediment. The biogenic structures produced included surface mounds and depressions; layer truncations; surficial and subsurficial sinuous, bilobate trails; isolated-to-connected, U- to V-shaped divots; flame structures; and open burrows. The size and diversity of biogenic structures produced by $C$. ocellatus changed with variations in sediment grain size and moisture content. Biogenic structures tended to be better defined in fine-grained sand. The width of the isolated U- to V-shaped divots was greater in the medium- and coarse-grained sand. Connected U-to V-shaped divots only occurred in the dry, fine- and medium-grained sand whereas open burrows were only produced in moist sand. While engaged in sand swimming the skinks altered grain sorting, loosened the sediment fabric, increased porosity and permeability, and added organic matter in the form of food remnants, fecal material, and shed skin. Data collected in this study can be used to better interpret terrestrial trace fossil assemblages in arid, eolian paleoenvironments to better assess the paleoecology of these ancient settings.
\end{abstract}

Angeline M. Catena. Department of Biology, Case Western Reserve University, 10900 Euclid Avenue, Cleveland, Ohio, 44106. angeline.catena@case.edu Daniel I. Hembree (corresponding author). Department of Geological Sciences, Ohio University, 316 Clippinger Laboratories, Athens, OH, 45701. hembree@ohio.edu

Keywords: trace fossil; ichnofossil; bioturbation; eolian; reptile; continental 


\section{INTRODUCTION}

Trace fossils are biologically produced structures that result from the movement of an organism on or through a medium. They record the behaviors and life activities of organisms including locomotion, dwelling, escape, and the search for food (Bromley, 1996). Trace fossils are produced and preserved in place and are very rarely transported out of the environment. As products of organism behavior, the types, abundances, and distributions of trace fossils are strongly controlled by the environment. As a result, trace fossils are invaluable to paleoenvironmental and paleoecological reconstructions. While a relatively new field in comparison to marine ichnology, recent studies of extinct continental organisms, along with studies of modern analogs, have demonstrated the value of continental ichnology (Voorhies, 1975; Martin and Bennett, 1977; Retallack et al., 1984; Smith, 1987; Groenewald et al., 2001; Hasiotis, 2002; Damiani et al., 2003; Hasiotis, 2003, 2004; Hembree et al., 2004; Gobetz and Martin, 2006; Hembree and Hasiotis, 2006, 2007, 2008; Smith and Hasiotis, 2008; Smith et al., 2008; Counts and Hasiotis, 2009; Hembree, 2009; Halfen and Hasiotis, 2010; Melchor et al., 2010; Hembree et al., 2012; Getty et al., 2013; Hembree, 2013).

Despite the current expansion of continental ichnology, few ichnological studies have examined the traces produced by desert-dwelling faunas (e.g., Young and Morain, 2003; Loope, 2006; Hembree and Hasiotis, 2007; Loope, 2008; Hembree et al., 2012). Although active sand dunes support the lowest faunal biomass of any terrestrial ecosystem, most desert-dwelling organisms such as skinks, snakes, spiders, and scorpions have fossorial habits in order to cope with the unstable substrates and the high surface temperatures present in modern dune fields (Robinson and Seely, 1980; Loope, 2006, 2008; Maladen et al., 2009).

Dry dune sand is not a cohesive media; as a result open burrows cannot typically be maintained in modern dune fields (Loope, 2006). Most animals that burrow in these sediments, therefore, do so by intrusion without producing open structures and are referred to as sand swimmers (Hembree and Hasiotis, 2007; Maladen et al., 2009; Vitt and Caldwell, 2013). Sand swimming has been adapted by many small, desert-dwelling vertebrates as an efficient means of moving beneath the sand surface (Loope, 2006). The biogenic structures produced by sand-swimming organisms are dependent on the consistency and the moisture content of the sediment as well as the morphology of the trace- maker (Bromley, 1996; Hasiotis, 2002). Sandswimming traces are diverse and can range from the disruption of sedimentary features to the complete homogenization of the sediment (Bromley, 1996; Hasiotis, 2002; Loope, 2006; Hembree and Hasiotis, 2007). Laboratory-based neoichnological experiments are necessary to identify the diverse suite of traces that can be produced by modern sand-swimming vertebrates as well as the environmental controls on their formation.

The purpose of this paper is to document the biogenic structures produced by a species of sandswimming skink, Chalcides ocellatus, in order to improve the interpretation of continental trace fossils in semiarid to arid, eolian environments. This includes a study of the relationship between sandswimming behaviors and trace fossils as well as the degree to which sand-swimming organisms modify loose, eolian deposits. This paper describes the basic morphologies of biogenic structures produced by $C$. ocellatus under both constant and varied environmental conditions. Sediment properties, including composition and moisture content, were altered to determine how the characteristics of each skink's biogenic structures changed in response to these commonly variable factors.

\section{Sand Skink Ecology and Behavior}

Despite their extensive evolutionary history from the Triassic to the recent and a geographic range that includes every continent except Antarctica (Datta and Ray, 2006), terrestrial lizards (Reptilia: Squamata) are a poorly studied group of burrowing animals. Few trace fossils, other than tracks, have been attributed to lizards and fewer neoichnological experiments have been conducted with burrowing lizards (e.g., Traeholt, 1995; Gupta and Sinha, 2001; Young and Morain, 2003; Hasiotis and Bourke, 2006; Hembree and Hasiotis, 2006, 2007; Catena and Hembree, 2014). Among lizards, skinks (Squamata: Scincidae) are the most diverse group, comprising the second largest of the lizard families with over 1200 extant species (Vitt and Caldwell, 2013). Skinks are easily distinguished from other lizards by their cylindrical bodies, shortened legs, cone-shaped heads, and tapered tails (Vitt and Caldwell, 2013). Skinks inhabit diverse environments that range from tropical to arid, including deserts, and most are either ground dwellers or burrowers (Pasteur, 1981; Shenbrot and Krasnov, 1997; Vitt and Caldwell, 2013). Fossil skinks have been found in strata as old as the Cretaceous (Estes, 1969) and in Paleocene, Oligocene, and Miocene sedimentary rocks in North 

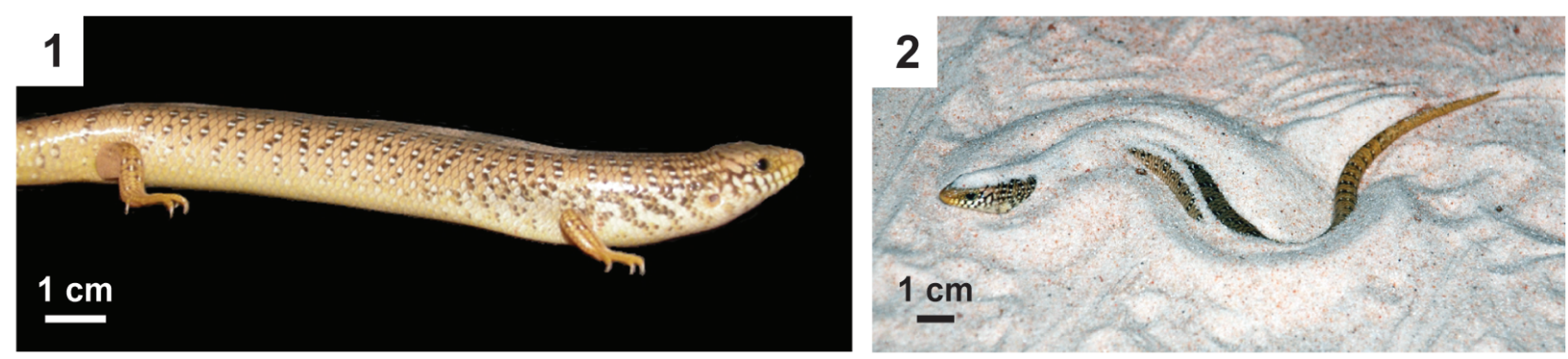

FIGURE 1. 1, The sand skink Chalcides ocellatus. 2, Sand skink engaged in sand swimming near the sediment surface.

America and Australia (Estes, 1969; Wellstead, 1982; Martin et al., 2004). Due to their abundance in the recent, their widespread occurrence in a variety of habitats, and their common burrowing nature, skinks have excellent potential for a trace fossil record as well.

Chalcides ocellatus, or the ocellated sand skink (Figure 1), is the most ancestral species of the genus Chalcides (Pasteur, 1981). Chalcides ocellatus inhabits arid environments across a wide geographic range that includes southernmost Europe, northern Africa, and western Asia (Pasteur, 1981; Shenbrot and Krasnov, 1997; Attum et al., 2007). This species is easily distinguished from other skinks by its highly reduced limbs and eyelike spots, which cover its back and sides (Bartlett and Bartlett, 1997). Known to be a generalist sand swimmer, C. ocellatus burrows for protection and thermoregulation in sedimentary environments including sand dunes with and without rocky outcrops, gravel plains, and river beds (Pasteur, 1981; Shenbrot and Krasnov, 1997; Attum et al., 2007). Adult C. ocellatus have a snout-vent length (SVL) of $15.0-30.5 \mathrm{~cm}$, are viviparous, and insectivorous (Bartlett and Bartlett, 1997).

\section{MATERIALS AND METHODS}

The burrowing behaviors of six individuals of Chalcides ocellatus were observed during this study. Individuals of $C$. ocellatus had an average SVL of $10.4 \mathrm{~cm}(8.0-11.5 \mathrm{~cm})$, an average trunk width of $1.7 \mathrm{~cm}(1.4-1.8 \mathrm{~cm})$, an average height of $1.1 \mathrm{~cm}(0.9-1.2 \mathrm{~cm})$, and had an average weight of $12.2 \mathrm{~g}(5.5-15.4 \mathrm{~g})$. Multiple skinks were used in order to delineate variations in biogenic structures due to differences in individual behavior. The laboratory was set to $25^{\circ} \mathrm{C}$ with $20 \%$ humidity and kept on a 12-hour light/dark cycle. The air temperature within the terrariums was brought to $32^{\circ} \mathrm{C}$ with the use of infrared, ceramic heat lamps set on a 12hour timer that matched the light timer. A rock was placed directly underneath the heat lamp to allow basking, and a water dish was placed on the opposite side of the terrarium to provide a cooling area. UVB lights set on a 12-hour timer matching the lights and heat lamps were also used in all of the terrariums.

The first set of experiments (Experiment 1) was designed to observe and record the natural burrowing behavior of a single sand skink under its natural average sediment composition and moisture conditions (Table 1.1). Results from Experiment 1 revealed the basic morphologies of biogenic structures produced by the sand skinks and served as a control with which to compare the experiments involving variations in sediment conditions. Each skink was placed in $38 \mathrm{~L}(50 \times 25 \times 30$ $\mathrm{cm})$ and $114 \mathrm{~L}(80 \times 35 \times 40 \mathrm{~cm})$ terrariums filled with ten, $1-\mathrm{cm}$-thick layers of loose, dry $(0 \%$ moisture), fine-grained $(0.125-0.25 \mathrm{~mm})$ quartz sand of alternating color (red and tan) to a depth of $10 \mathrm{~cm}$ (Figure 2.1). The terrariums were prepared with alternating layers of colored sand in order to better observe the biogenic structures produced by the skinks. Terrariums of different sizes were used in order to evaluate the influence of available space on the morphology and distribution of the biogenic structures. Trials of Experiment 1 were run for periods of 7 and 14 days. The two different experiment durations were used to determine the effect of time on the morphology and abundance of biogenic structures produced.

The second set of experiments (Experiment 2) was designed to observe the burrowing behaviors and biogenic structures produced by Chalcides ocellatus in different sediment types within the natural ranges of the species including average grain size and density (Table 1.2). In Experiment 2, 38 and $114 \mathrm{~L}$ terrariums were prepared with ten, $1-\mathrm{cm}-$ thick layers of either medium- $(0.25-0.5 \mathrm{~mm})$ or coarse-grained $(0.5-1.0 \mathrm{~mm})$ sand. A third set of trials was then conducted with a fining-upward sequence composed of layers of fine-, medium-, 
TABLE 1. Experimental parameters. 1, Basic morphology experiments. 2, Increased grain size experiments. 3, Increased sediment moisture experiments. C.O: Chalcides ocellatus specimen number. Grain size: FS: fine-grained sand, MS: medium-grained sand, CS: coarse-grained sand, AS: alternating fine-, medium-, and coarse-grained sand.

\begin{tabular}{cccccc}
\multicolumn{7}{c}{ 1. Experiment 1: Basic Morphology } \\
\hline Specimen & Terrarium & Grain Size & Temperature & $\%$ Moisture & Time (days) \\
\hline C.O 7 & $38 \mathrm{~L}$ & FS & $32^{\circ} \mathrm{C}$ & 0 & 7 \\
C.0 2 & $38 \mathrm{~L}$ & FS & $32^{\circ} \mathrm{C}$ & 0 & 7 \\
C.0 4 & $114 \mathrm{~L}$ & FS & $32^{\circ} \mathrm{C}$ & 0 & 7 \\
C.O 6 & $114 \mathrm{~L}$ & FS & $32^{\circ} \mathrm{C}$ & 0 & 7 \\
C.O 2 & $38 \mathrm{~L}$ & FS & $32^{\circ} \mathrm{C}$ & 0 & 14 \\
C.O 6 & $38 \mathrm{~L}$ & FS & $32^{\circ} \mathrm{C}$ & 0 & 14 \\
C.0 4 & $114 \mathrm{~L}$ & FS & $32^{\circ} \mathrm{C}$ & 0 & 14 \\
C.O 7 & $114 \mathrm{~L}$ & FS & $32^{\circ} \mathrm{C}$ & 0 & 14
\end{tabular}

2. Experiment 2: Grain Size

\begin{tabular}{cccccc}
\hline Specimen & Terrarium & Grain Size & Temperature & $\%$ Moisture & Time (days) \\
\hline C.0 7 & $38 \mathrm{~L}$ & $\mathrm{MS}$ & $32^{\circ} \mathrm{C}$ & 0 & 14 \\
$\mathrm{C} .08$ & $38 \mathrm{~L}$ & $\mathrm{MS}$ & $32^{\circ} \mathrm{C}$ & 0 & 14 \\
$\mathrm{C} .04$ & $114 \mathrm{~L}$ & $\mathrm{MS}$ & $32^{\circ} \mathrm{C}$ & 0 & 14 \\
C.0 2 & $114 \mathrm{~L}$ & $\mathrm{CS}$ & $32^{\circ} \mathrm{C}$ & 0 & 14 \\
C.0 7 & $38 \mathrm{~L}$ & $\mathrm{CS}$ & $32^{\circ} \mathrm{C}$ & 0 & 14 \\
C.0 2 & $38 \mathrm{~L}$ & $\mathrm{CS}$ & $32^{\circ} \mathrm{C}$ & 0 & 14 \\
C.0 8 & $114 \mathrm{~L}$ & $\mathrm{CS}$ & $32^{\circ} \mathrm{C}$ & 0 & 14 \\
C.0 6 & $114 \mathrm{~L}$ & AS & $32^{\circ} \mathrm{C}$ & 0 & 14 \\
C.0 6 & $38 \mathrm{~L}$ & AS & $32^{\circ} \mathrm{C}$ & 0 & 14 \\
C.0 4 & $38 \mathrm{~L}$ & AS & $32^{\circ} \mathrm{C}$ & 0 & 14 \\
C.0 2 & $114 \mathrm{~L}$ & AS & $32^{\circ} \mathrm{C}$ & 0 & 14 \\
C. 07 & $114 \mathrm{~L}$ & AS & $32^{\circ} \mathrm{C}$ & 0 & 14
\end{tabular}

3. Experiment 3: Sediment Moisture

\begin{tabular}{cccccc}
\hline Specimen & Terrarium & Grain Size & Temperature & $\%$ Moisture & Time (days) \\
\hline C.O 4 & $38 \mathrm{~L}$ & FS & $32^{\circ} \mathrm{C}$ & 20 & 14 \\
C.O 2 & $38 \mathrm{~L}$ & FS & $32^{\circ} \mathrm{C}$ & 20 & 14 \\
C.O 6 & $114 \mathrm{~L}$ & FS & $32^{\circ} \mathrm{C}$ & 20 & 14 \\
C.O 7 & $114 \mathrm{~L}$ & FS & $32^{\circ} \mathrm{C}$ & 20 & 14
\end{tabular}

and coarse-grained sand. Each of the trials of Experiment 2 was run for a period of 14 days.

The third set of experiments (Experiment 3 ) was designed to observe the effect of increased sediment moisture on skinks' burrowing behaviors (Table 1.3). Sediment moisture levels were measured with an Aquaterr multimeter (EC-300) at the start and end of each trial. The sediment moisture was maintained at $20 \%$. The surface of each terrarium was regularly sprayed with water during the experiments to maintain this moisture level. Trials of Experiment 3 were run for 14 days.

Biogenic structures produced by Chalcides ocellatus at the surface and against the sides of 

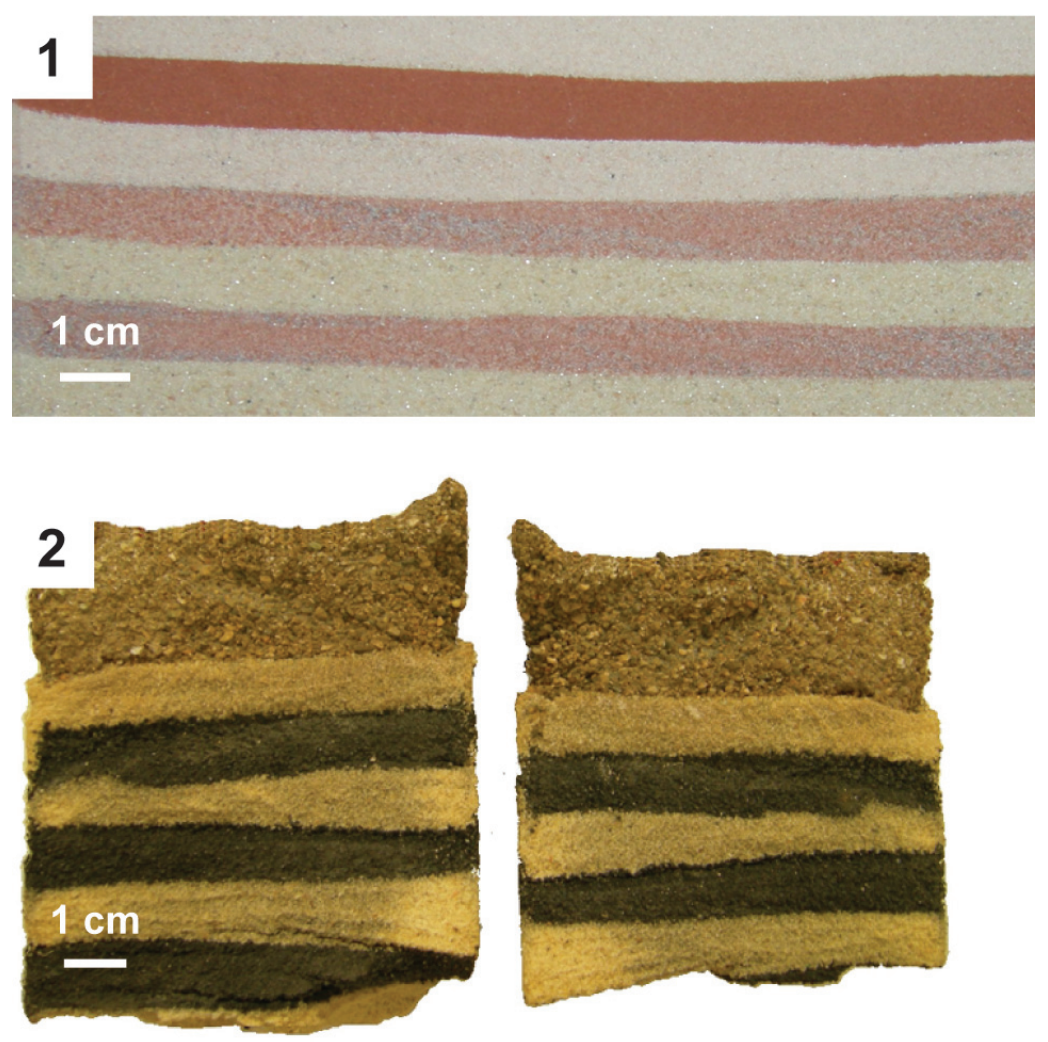

FIGURE 2. 1, Initial stratification of a terrarium filled with ten, 1-cm-thick layers of fine-grained sand. 2, Vertical cut through a core of undisturbed 1-cm-thick layers of coarse-grained sand.

the terrariums were photographed daily during each trial. Videos were made if the skinks were actively burrowing during times of observation. At the end of the trials the sand skinks were removed from terrariums and placed in temporary holding tanks. The skinks were removed only after the animals exited the sediment to engage in feeding or basking behaviors. Once the skinks were removed, the four sides of the terrarium were photographed to document any visible biogenic structures. Portions of the sand in the interior of the terrarium were then bound with a sodium silicate solution. To do this, three to four, $10-\mathrm{cm}$ diameter, aluminum tubes were inserted vertically into the sand lengthwise down the center of the tanks. The sediment within the tubes was capped with a coarse sand of contrasting composition to that used in the trials in order to preserve any surface features and to minimize sediment disruption from the pouring of the binding solution. The tubes were left in place to harden for approximately seven days and then removed. The metal tubes were opened to extract the bound sand cores which were cut into sections so that biogenic structures could be photographed and described (Figure 2.2).
The biogenic structures produced by the sand skinks were described qualitatively including their general shape and orientation relative to the surface and sediment layers. Quantitative data was collected when possible including depth, length, height, and width. Where more than 10 structures of a similar architecture that included quantitative data were described from each sediment type, these properties were compared using the nonparametric Mann-Whitney test. The Mann-Whitney test is used to determine if two samples are from the same population by comparing the similarity of their medians. If the resulting $p$ values are $<0.05$ then the median values are considered significantly different.

\section{EXPERIMENTAL RESULTS}

The three experiments resulted in very similar burrowing behaviors and resulting assemblages of biogenic structures. There was some variation in the abundance and diversity of the biogenic structures as well as some quantitative properties. The general bioturbation patterns and specific architectures of biogenic structures for all of the experiments are, therefore, presented together. Specific 

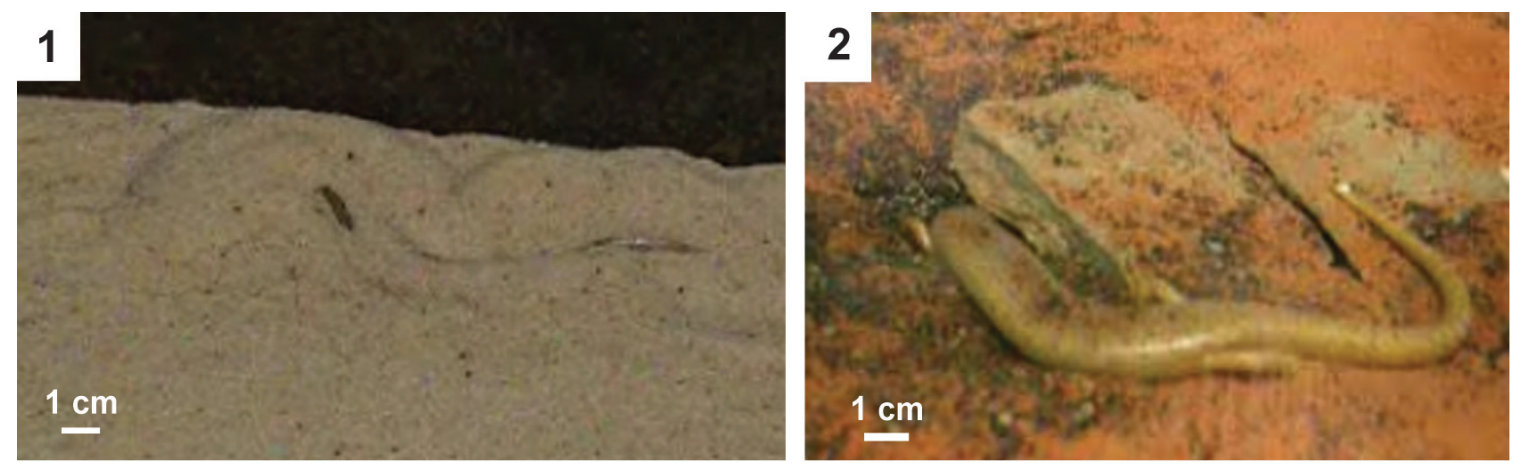

FIGURE 3. Videos (see online) of the burrowing techniques of Chalcides ocellatus. 1, Burrowing by sand swimming or intrusion. 2, Burrowing by excavation.

differences in the morphology and occurrence of the structures are presented with each description. The overall effects of environmental conditions on the sand skink's burrowing behavior and biogenic structures are summarized at the end.

\section{General Bioturbation Patterns}

Individuals of Chalcides ocellatus began to burrow at the surface of the dry, loose sand by plunging their cone-shaped heads into the sand while pushing on the sediment surface with their front legs. Once enough traction was gained, the sand skinks pressed their front and hind legs against their bodies and propelled themselves through the loose sand with lateral undulations of the entire body and tail (Figure 3.1).

Sediment disturbance produced by sand swimming reached a maximum depth of $4.2 \mathrm{~cm}$, although the greatest activity occurred within the upper $2.0 \mathrm{~cm}$. In general, the amount of bioturbation decreased with depth and was greatest near the basking rock placed directly under the heat lamp in each terrarium. Bioturbation at the surface included surficial sand-swimming traces (Figure 3.1) and homogenization of the upper 1-2 sand layers. At depths greater than $1.0 \mathrm{~cm}$ near the heat lamps and at depths greater than $0.5 \mathrm{~cm}$ in other areas of the terrariums, the degree of homogenization decreased and distinct biogenic structures could be discerned. These structures largely resulted from the disruption of sediment layers by the lateral undulation of Chalcides ocellatus below the surface of the sediment. Subsurface structures were less commonly caused by the transport of sediment downward and upward through the sand layers; this occurred when $C$. ocellatus burrowed deeply into the sediment and then quickly returned to the surface to feed or bask.
Chalcides ocellatus was also observed to burrow by excavation in the presence of an obstacle such as a rock or the terrarium wall. During excavation, $C$. ocellatus removed the sediment from underneath, or adjacent to, the obstacle by shoveling the sand behind its body with its front legs while stabilizing itself with its hind legs (Figure 3.2).

The greatest amount and diversity of bioturbation was present in trials with dry, fine-grained sand, whereas the lowest occurred in trials with dry, coarse-grained sand. The greatest depth of bioturbation, however, occurred in trials with moist, medium- and coarse-grained sand.

\section{Sand-Swimming Biogenic Structures}

Sand swimming in loose sediments resulted in several biogenic structures. Most of the biogenic structures were replicated in all of the trials despite changes in terrarium size, grain size, and sediment moisture.

Mounds and Depressions. Simple, surficial biogenic structures observed in terrariums and cores that consisted of mounds of sediment and accompanying depressions $(n=24)$ (Figure 4.1). Mounds and depressions were produced in each set of experiments and were associated with layer homogenization and truncation. The average width and height or depth of the mounds and depressions at the end of the trials were $5.1 \mathrm{~cm}$ and $1.0 \mathrm{~cm}$, respectively. Smaller mounds and depressions $(\sim 2.0 \mathrm{~cm}$ wide and $\sim 0.5 \mathrm{~cm}$ high) were directly observed being produced during times of active burrowing. Most of the mounds and depressions were produced by the displacement of sand grains during Chalcides ocellatus' initial entry into the sediment. Some were also produced by undulatory locomotion at or near the sediment surface. The production of mounds greater than $2.0 \mathrm{~cm}$ in width 

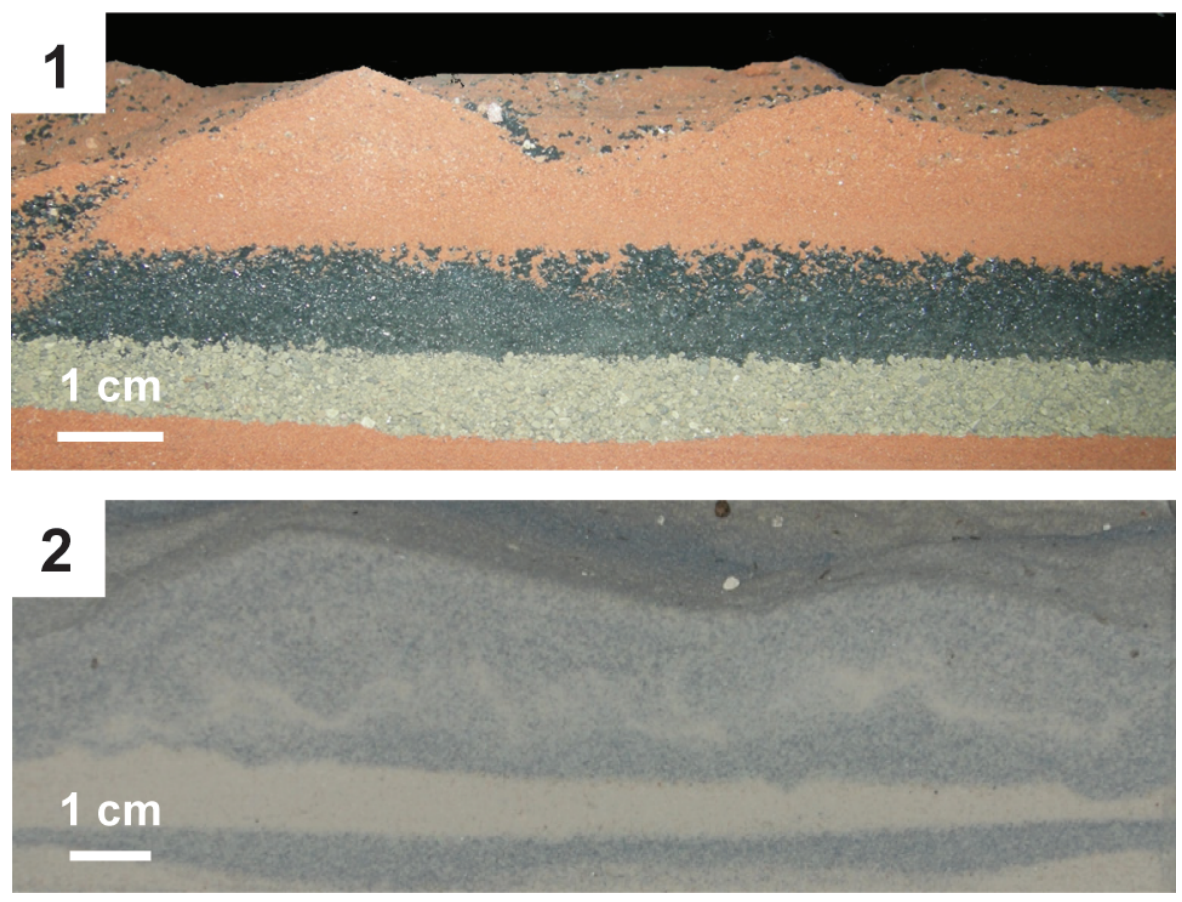

FIGURE 4. 1, A sequence of surficial mounds and depressions in an experiment with alternating sand grain sizes. 2, A terrarium showing the homogenization of the upper $2 \mathrm{~cm}$ of fine-grained sand.

was not observed during active burrowing, but may have been the result of burrowing by excavation.

Homogenization. Homogenization consisted of the mixing of sand layers with different colors or grain sizes $(n=28)$ (Figure 4.2). This surficial to subsurficial feature was observed against terrarium walls and in sand cores in all trials and was associated with mounds and layer truncations. The depth of observed homogenization was between 1.0 and $4.0 \mathrm{~cm}$, with an average depth of $1.6 \mathrm{~cm}$. In fine-, medium-, and coarse-grained sand average homogenization depth was $1.6,1.7$, and $1.7 \mathrm{~cm}$, respectively. Using the Mann-Whitney test, the median depth of homogenization was not found to be significantly different between grain sizes (Table 2.1). Homogenization was observed during burrowing by excavation and vertical, sand-swimming locomotion by the skinks. Homogenization was also produced by repeated undulatory movements through the subsurface of the same area, causing sand from the overlying layer to collapse and mix with the underlying layer.

Surficial Sinuous Bilobate Trails (SSBT). SSBT $(n=10)$ are complex, surface structures characterized by smooth, alternating concave to convex edges, with or without a medial ridge (Figure 5.1). SSBT were produced in all three experiments. The SSBT are linear to sinuous, $16.0-118.7 \mathrm{~cm}$ in length, with an average width and wavelength of
$3.4 \mathrm{~cm}$ and $7.5 \mathrm{~cm}$, respectively. The SSBT observed in dry, fine sand were more sharply defined and were also more likely to contain a medial ridge (Figure 5.1) than those in the moist or medium- to coarse-grained sand (Figure 5.2). The SSBT were produced by the undulatory movement of the skinks while engaged in sand-swimming locomotion just beneath the surface of the sediment (Figure 3.1).

Subsurficial Sinuous Trails (SST). A SST $(n=1)$ was observed in one set of cores in dry, fine-grained sand, $1.5 \mathrm{~cm}$ below the surface (Figure 5.3-4). The SST was exposed along the bedding plane of a broken core. The SST strongly resembles the SSBT, but lacks the two lobes and medial ridge. The SST had an average width of $1.6 \mathrm{~cm}$ and an average wavelength of $4.2 \mathrm{~cm}$. SST resulted from the undulatory movement of the skink below the sediment surface.

Layer Truncations. Biogenic structures consisting of the truncation or gradual pinching out of a layer of sediment $(n=14)$ (Figure 6.1). These subsurficial structures were observed in dry, fine-, medium-, coarse-, and alternating sand in association with mounds, depressions, and homogenization. One to three layers were truncated to an average depth of $1.4 \mathrm{~cm}$. Layer truncations were the result of the sand skink burrowing by excavation through the sand layers. 
TABLE 2. Quantitative properties of sand skink structures in fine- (FS), medium- (MS), and coarse-grained (CS) sand. 1, Depth of homogenization. 2, Width of U- to V-shaped divots. 3, Height of U- to V-shaped divots. All values are in $\mathrm{cm}$. Bold values are the calculated mean for the structures produced in each grain size. Italicized values are the $p$ values from a two sample Mann-Whitney test; values $<0.05$ indicate a significant difference in the median rank value.

\begin{tabular}{|c|c|c|c|c|c|c|c|c|}
\hline \multicolumn{3}{|c|}{ 1. Homogenization Depth } & \multicolumn{3}{|c|}{ 2. Divot Width } & \multicolumn{3}{|c|}{ 3. Divot Height } \\
\hline FS & MS & cs & FS & MS & cs & FS & MS & cs \\
\hline 0.8 & 0.9 & 0.7 & 0.6 & 1.6 & 1.8 & 0.2 & 0.6 & 0.4 \\
\hline 1.1 & 1 & 1 & 0.7 & 1.6 & 2.0 & 0.2 & 0.6 & 0.4 \\
\hline 1.2 & 1.4 & 1.1 & 0.8 & 2.1 & 2.1 & 0.2 & 0.7 & 0.6 \\
\hline 1.3 & 1.6 & 1.1 & 0.8 & 2.3 & 2.5 & 0.2 & 0.7 & 0.7 \\
\hline 1.3 & 1.6 & 1.2 & 0.9 & 3.1 & 3.6 & 0.3 & 0.8 & 0.8 \\
\hline 1.5 & 1.9 & 1.3 & 1.0 & 3.5 & 6.0 & 0.3 & 0.8 & 1.0 \\
\hline 1.6 & 2.1 & 2.1 & 1.1 & 3.6 & & 0.3 & 0.9 & \\
\hline 1.7 & 2.4 & 2.4 & 1.2 & 4.1 & & 0.3 & 1.0 & \\
\hline 1.8 & 2.6 & 4 & 1.3 & 4.2 & & 0.4 & 1.1 & \\
\hline \multirow[t]{2}{*}{3.3} & & & 1.5 & 4.4 & & 0.4 & 1.4 & \\
\hline & & & 1.5 & 4.6 & & 0.4 & 1.4 & \\
\hline \multirow[t]{2}{*}{1.6} & 1.7 & 1.7 & 1.5 & 5.2 & & 0.4 & 1.9 & \\
\hline & & & 1.5 & & & 0.5 & & \\
\hline FS/MS & $p=0.390$ & & 1.6 & & & 0.5 & & \\
\hline FS/CS & $p=0.623$ & & 1.6 & & & 0.5 & & \\
\hline \multirow[t]{23}{*}{$M S / C S$} & $p=0.507$ & & 1.8 & & & 0.5 & & \\
\hline & & & 1.8 & & & 0.5 & & \\
\hline & & & 1.8 & & & 0.5 & & \\
\hline & & & 1.8 & & & 0.5 & & \\
\hline & & & 1.8 & & & 0.6 & & \\
\hline & & & 1.9 & & & 0.6 & & \\
\hline & & & 2.1 & & & 0.6 & & \\
\hline & & & 2.1 & & & 0.6 & & \\
\hline & & & 2.1 & & & 0.6 & & \\
\hline & & & 2.1 & & & 0.7 & & \\
\hline & & & 2.3 & & & 0.7 & & \\
\hline & & & 2.4 & & & 0.8 & & \\
\hline & & & 2.4 & & & 0.9 & & \\
\hline & & & 2.6 & & & 0.9 & & \\
\hline & & & 2.8 & & & 1.0 & & \\
\hline & & & 3.3 & & & 1.0 & & \\
\hline & & & 3.7 & & & 1.2 & & \\
\hline & & & 4.2 & & & 1.3 & & \\
\hline & & & 4.7 & & & 2.4 & & \\
\hline & & & 1.9 & 3.3 & 3.0 & 0.6 & 1.0 & 0.7 \\
\hline & & & $F S / M S$ & $p=0.001$ & & FS/MS & $p=0.001$ & \\
\hline & & & $F S / C S$ & $p=0.048$ & & FS/CS & $p=0.434$ & \\
\hline & & & $M S / C S$ & $p=0.452$ & & $M S / C S$ & $p=0.073$ & \\
\hline
\end{tabular}



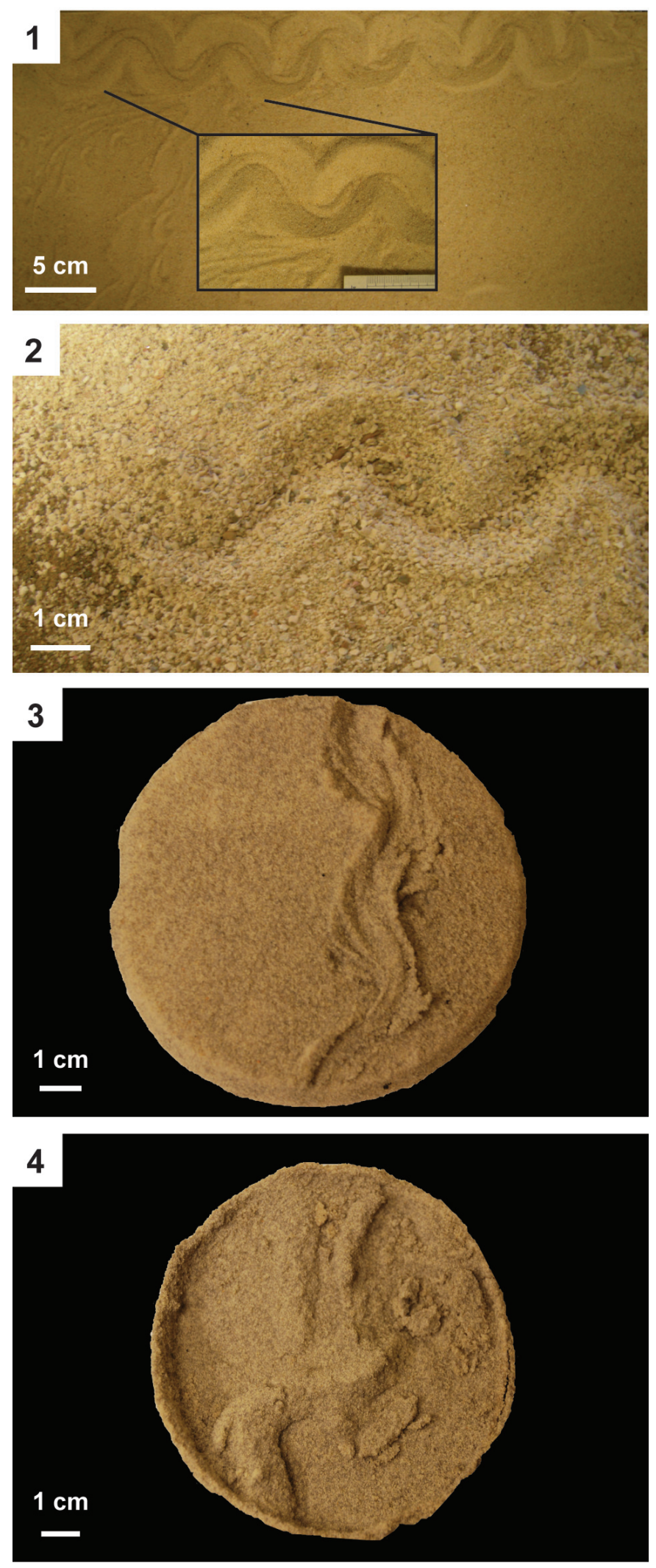

FIGURE 5. 1, Surficial sinuous bilobate trail (SSBT) in medium-grained sand with an enlarged view (insertion). 2, SSBT in coarse-grained sand. 3, A subsurficial sinuous trail from the lower portion of a core from fine-grained sand. 4, SST from the upper portion of a core from fine-grained sand. 

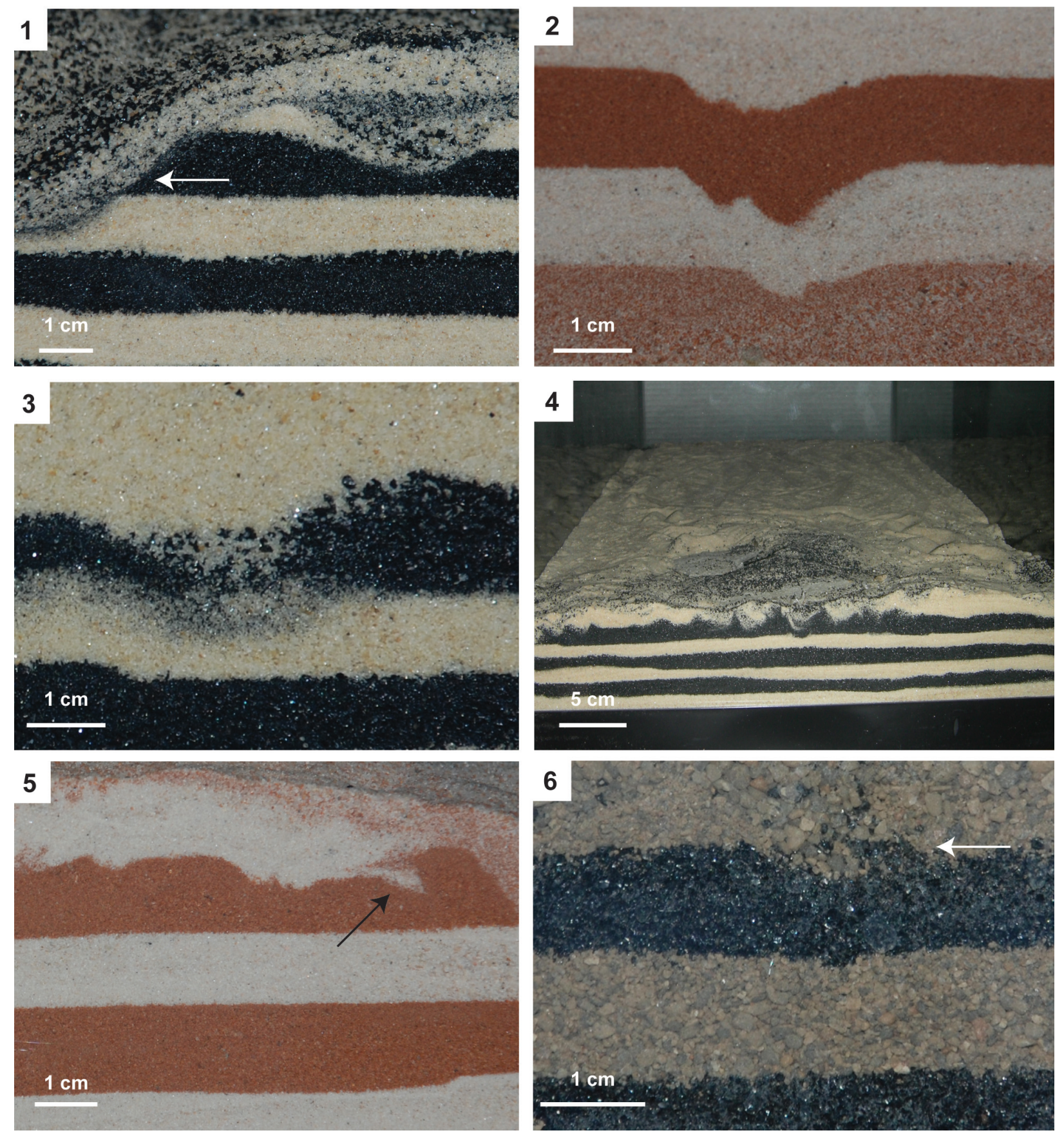

FIGURE 6. 1, Truncation of the upper $2 \mathrm{~cm}$ of medium-grained sand (at arrow) and an infilled surficial depression. 2, An isolated U-shaped divot with a sharp boundary in fine-grained sand. 3, An isolated U-shaped divot with a gradational boundary in medium-grained sand. 4, Connected U- to V-shaped divots with gradational boundaries in mediumgrained sand. 5, A sharply defined flame structure (arrow) and an accompanying U-shaped divot in fine-grained sand. 6, A small flame structure (arrow) in coarse-grained sand. 
Isolated U- to V-Shaped Divots. Isolated U- to Vshaped divots $(n=33)$ were vertically to subvertically oriented, antiformal and synformal, U- to Vshaped structures with smooth walls and sharp to gradational contacts with the surrounding sediment (Figure 6.2-3). These subsurficial structures were observed against terrarium walls and cores in all trials. The divots had an average width of $2.4 \mathrm{~cm}$ and an average height of $0.7 \mathrm{~cm}$. The average width of the isolated U-to V-shaped divots produced in the coarse- and medium-grained sand was greater than in those produced in fine-grained sand, being $3.0,3.3$, and $1.9 \mathrm{~cm}$, respectively. The average divot height showed less variation between grain sizes at $0.7,1.0$, and $0.6 \mathrm{~cm}$ respectively. The results of the Mann-Whitney test indicated that there was no significant difference in the median width of the divots produced in mediumand coarse-grained sand; there was a significant difference between the widths of divots produced in both of these grain sizes and the fine-grained sand (Table 2.2). In comparing median height of the divots, however, only divots in the fine- and mediumgrained sand were found to be significantly different (Table 2.3). Isolated U- to V-shaped divots were produced by the lateral undulations of the sand skinks below the surface of the sediment. As the skink moved, it formed small depressions in the underlying sand layer that were then filled in by the collapse of the overlying layer after the skink moved forward.

Connected U- to V-Shaped Divots. Less common sequences of two or more $\mathrm{U}$ - to $\mathrm{V}$-shaped divots $(n=10)$ were observed against terrarium walls and in cores (Figure 6.4). Connected U- to V-shaped divots were produced in fine- and medium-grained sand; however, more occurred in the mediumgrained sand $(n=6)$. Connected $U$ - to $V$-shaped divot sequences observed against the terrarium walls had between 2 and 11 divots. The average width and height of the connected divot sequences were $7.0 \mathrm{~cm}$ and $1.3 \mathrm{~cm}$, respectively. Connected $\mathrm{U}$ - to V-shaped divots were likely the result of extended undulatory locomotion beneath the sediment surface.

Flame Structures. Small biogenic structures $(n=21)$ observed against terrarium walls and in cores consisting of horizontally to subhorizontally oriented strands of sand grains extending upward from the margin of a $\mathrm{U}$ - to $\mathrm{V}$-shaped divot into the overlying layer (Figure 6.5-6). The average width and height of the flame structures were $1.5 \mathrm{~cm}$ and $0.7 \mathrm{~cm}$, respectively. Flame structures were produced in dry to moist, fine- and coarse-grained sand, but were mostly produced in dry, fine-grained sand $(n=19)$. The flame structures in the dry, finegrained sand (Figure 6.5) were also more sharply defined than those in the coarse-grained sand (Figure 6.6). The flame structures were the result of the lateral undulatory movement of the sand skink below the sediment surface followed by either a reversal in direction or upward movement.

\section{Open Burrows}

Temporary (2-12 days) open burrows $(n=7)$ were observed in terrariums filled with moist sand (Figure 7.1). The entrances to the open burrows had an average width of $1.4 \mathrm{~cm}$; one open burrow with a depth of $4.1 \mathrm{~cm}$ was observed against the wall of the terrarium. All open burrows were temporary and were either actively filled by the skink or collapsed as a result of repeated wetting and drying of the sand (Figure 7.2-3). Open burrows were the result of sand swimming and excavation through moist sand.

\section{Effects of Environmental Conditions}

There were some differences in the biogenic structures produced by Chalcides ocellatus associated with changes in sediment grain size and moisture content, but many aspects did not vary. For example, five of the eight structures were produced in all grain sizes. The exceptions were SST produced only in fine-grained sand, connected divots produced only in fine- and medium-grained sand, and flame structures produced only in fine- and coarse-grained sand. Despite their occurrence in all grain sizes, SSBT were more sharply defined and recognizable in the fine-grained sand. Likewise, connected divots were most common in the medium-grained sand, whereas flame structures were most common and more sharply defined in the fine-grained sand. The average depth of homogenization was similar $(1.6-1.7 \mathrm{~cm})$ across all three sand types (Table 2.1). The average width and height of both isolated and connected $\mathrm{U}$ - to $\mathrm{V}$ shaped divots, however, did vary across sand types (Table 2.2). Divots produced in medium- and coarse-grained sand were wider $(3.3$ and $3.0 \mathrm{~cm}$ ) than those produced in fine-grained sand $(1.9 \mathrm{~cm})$, whereas divots produced in medium-grained sand had a greater height $(1.0 \mathrm{~cm})$ than those in finegrained sand $(0.6 \mathrm{~cm})$. Therefore, on average, divots produced in medium-grained sand were larger than those produced in fine-grained sand.

Time and terrarium size did not have significant effects on the burrowing behaviors and the types of biogenic structures produced by the sand 

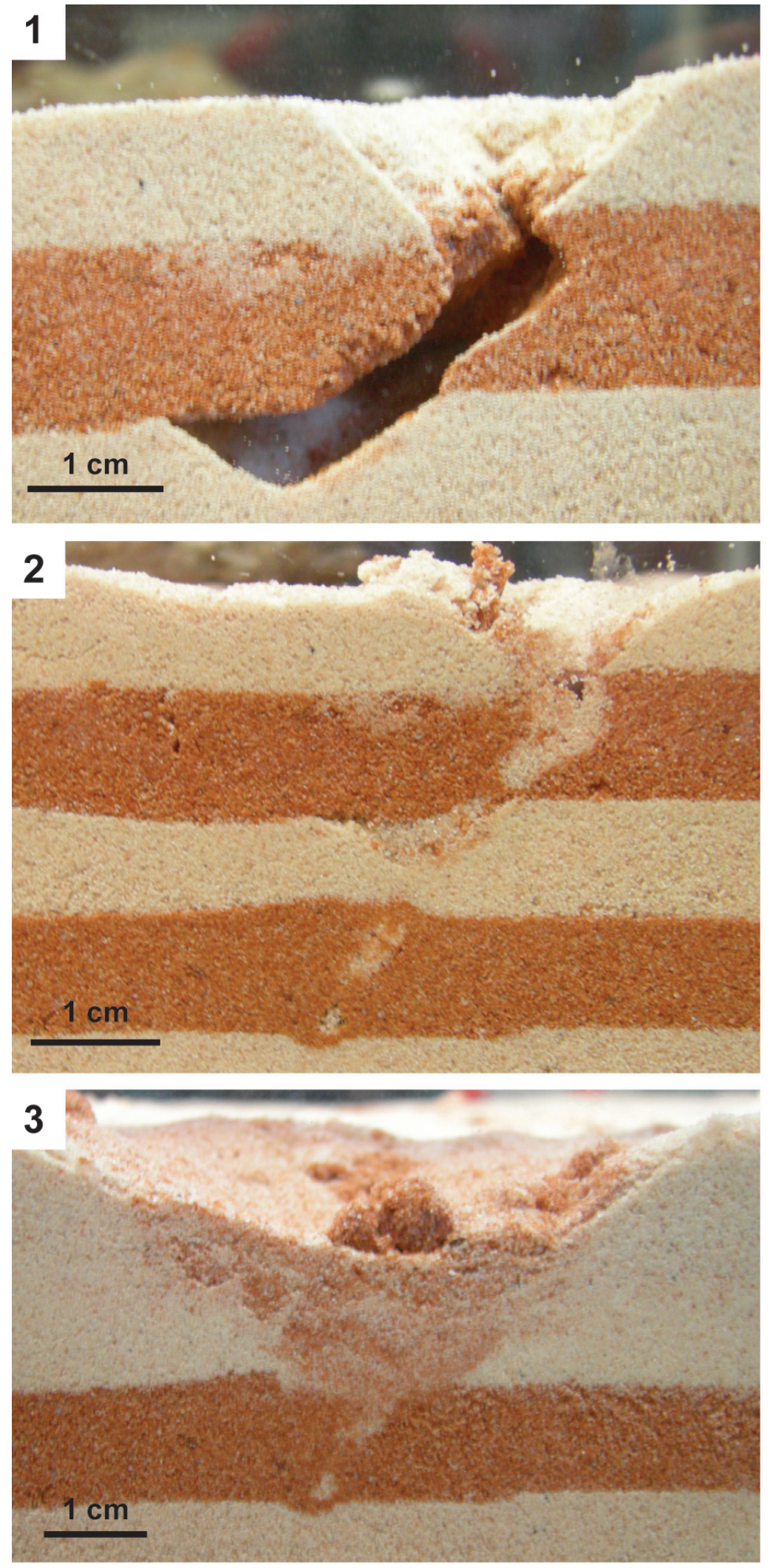

FIGURE 7. 1, Open burrow produced by Chalcides ocellatus in a terrarium with $20 \%$ sediment moisture. 2, The open burrow at day 12 of the trial. 3, The resulting biogenic structure from the collapse of the open burrow on day 14 of the trial. 
skinks. The abundance, reflected by the number produced in the terrarium, and density, reflected by the number in a single core, of biogenic structures, however, did vary. Experiments in $38 \mathrm{~L}$ terrariums averaged $4(1-10, \sigma=3.0)$ biogenic structures per terrarium and $4(0-9, \sigma=2.6)$ biogenic structures per core, whereas experiments in $114 \mathrm{~L}$ terrariums averaged $5(0-11 . \sigma=4.3)$ biogenic structures per terrarium but only $1(0-5, \sigma=1.8)$ biogenic structures per core. The experiments run for seven days had an average of six $(4-9, \sigma=2.1)$ biogenic structures per terrarium and three $(0-6 ; \sigma=3.2)$ biogenic structures per core, whereas the experiments run for fourteen days averaged only four $(0-12, \sigma=3.9)$ biogenic structures per terrarium and three $(0-9, \sigma=2.4)$ biogenic structures per core.

\section{DISCUSSION}

\section{Burrow Morphology and Tracemaker}

Chalcides ocellatus produced eight different types of biogenic structures. These biogenic structures were produced by different individuals of $C$. ocellatus and were duplicated in multiple experiments. The sizes of the biogenic structures produced were similar to the body sizes of the skinks used in the study. The U- to V-shaped divots, for example had an average width and height of 2.4 and $0.7 \mathrm{~cm}$, respectively, and the SST had an average width of $1.6 \mathrm{~cm}$. These values are similar to the average cross-sectional width $(1.7 \mathrm{~cm})$ and height $(1.1 \mathrm{~cm})$ of the skinks that produced these structures. Exceptions were the SSBT, which had an average width of $3.4 \mathrm{~cm}$, double the average width of the sand skink body. Given the nature of the skinks locomotion and the loose sediment, the size of the traces would not be expected to be an exact match to the tracemakers, but for most they are not very different. The larger size of the SSBT is likely a function of being produced at the surface where unconfined, loose sand grains are able to be displaced greater distances by the moving animal.

When engaged in sand swimming, the skinks did not use their limbs; they were instead pressed against the skinks body. As a result, no traces or bioglyphs were produced by the appendages. Any biogenic structures produced, therefore, reflect only the cylindrical body of the skink. Therefore, the biogenic structures produced through sand swimming are the product of a functionally limbless animal and should be similar to those of limbless lizards or snakes.

\section{Burrow Morphology and Behavior}

The biogenic structures produced by Chalcides ocellatus were the product of three general behaviors: locomotion, resting, and escape. The undulatory, sand-swimming locomotion style of $C$. ocellatus is strongly reflected in the isolated and connected U- to V-shaped divots, the SST and SSBT, and flame structures. The length of these structures and the sharpness of their contacts with the surrounding, undisrupted sediment are also reflective of the locomotory behavior of $C$. ocellatus. The curved points of the flame structures and their association with $U$ - to $V$-shaped divots indicate that they represent a change in the direction of locomotion in the subsurface. In doing so, the skinks pull a small amount of sand with them into adjacent sand layers.

The skinks' behavior within the sand also affected the types of boundaries around the biogenic structures, either gradational or abrupt. Biogenic structures with gradational boundaries were produced either when Chalcides ocellatus moved slowly or was relatively stationary and engaged in resting behavior. Gradational contacts were produced by small movements and adjustments made by the skink while beneath the surface. The biogenic structures with sharp contacts with the surrounding sediment were produced when the skink moved quickly for either simple locomotion or escape, minimizing the amount of mixing of sand grains across the boundary.

\section{Burrow Morphology and Sediment Properties}

The experiments conducted with varying sediment properties indicate that both grain size and moisture content influence the distribution, morphology, and abundance of the biogenic structures produced by Chalcides ocellatus. For example, the skinks were more frequently observed at the sediment surface during experiments with coarsegrained sand. Greenville and Dickman (2009) found that Lerista labialis, an Australian desertdwelling skink, preferentially selected habitats with soft, loose sand. It was hypothesized that the softer, looser sand facilitated movement by reducing the energetic cost of locomotion (Greenville and Dickman, 2009). It is possible that $C$. ocellatus also preferred moving into the finer-grained sand for this reason. The coarser grain size, therefore, likely deterred $C$. ocellatus from burrowing and producing biogenic structures.

The SSBT were most frequently observed in experiments with fine- and medium-grained sand. Similarly, the connected U- to V-shaped divots 
were observed in only fine- and medium-grained sand, but were primarily produced in the mediumgrained sand. The coarse-grained sand was likely too energetically costly for Chalcides ocellatus to burrow into, as suggested by the greater amount of time the skinks remained at the surface. Conversely, the fine-grained sand may have been too dense for the skinks to perform the sustained lateral undulatory locomotion in the subsurface necessary to produce the connected $U$ - to $V$-shaped divots. The flame structures were observed primarily in dry, fine-grained sand, and only once in both coarse-grained and moist sand The weight of the individual grains in the larger grain sizes and the increased density of the moist sand may have prevented most of the sand skinks from performing the complex, sand-swimming movements associated with the production of flame structures.

The properties of the different grain sizes also resulted in differential expression of the biogenic structures. The sharpness of the definition of the flame structures and the SSBT was directly related to grain size. Due to the consistency of the finegrained sand, the flame structures and the SSBT were more sharply defined and had greater detail than those produced in the medium- and coarsegrained sand. The greater average size of the $U$ - to V-shaped divots in the medium- and coarsegrained sand are likely the result of the different sizes of the individual sand grains; when moved coarser sand grains produce an overall larger area of disturbance than fine sand grains. Open burrows were the result of sand swimming in moist sediments; there was no change in behavior, but the pore water allowed the sediment particles to adhere to one another and maintain the void spaces produced by the skinks as they moved through the sediment.

The amount of time and space available for Chalcides ocellatus to burrow did not result in differences in the types of biogenic structures produced or the overall amount of bioturbation by the skinks. The only difference in the level of bioturbation related to terrarium size occurred in the cores. On average the cores from the $38 \mathrm{~L}$ terrariums contained more biogenic structures than the cores from the $114 \mathrm{~L}$ terrariums. The greater density of bioturbation in the $38 \mathrm{~L}$ terrariums results from the smaller available area and volume of sediment, whereas the lower density in the $114 \mathrm{~L}$ terrarium results from the larger available area and volume of sediment. The difference in bioturbation density, therefore, does not represent an important difference in the behavior of $C$. ocellatus, simply that the same areas were reworked multiple times given the experimental constraints; distinct types of biogenic structures were not produced by these different conditions.

\section{Significance}

Recognition of Sand-Swimming Skink Burrows in the Fossil Record. Although burrowing skinks are prevalent in the modern with a large geographic range and long evolutionary history, their burrows lack a significant presence in the fossil record. The failure to recognize burrows and other biogenic structures produced by skinks has likely resulted in this relative absence. In order to interpret the tracemakers of trace fossils, it is essential that we are able to recognize the architecture of burrows and other traces produced by modern burrowing animals. Trace fossils are classified according to a suite of ichnotaxonomic characters known as ichnotaxobases; these include aspects of ichnofossil morphology such as overall shape, orientation with respect to the sediment surface, architecture, and surficial features (Bromley, 1996; Bertling et al., 2006). An understanding of the burrows produced by modern organisms is necessary to establish a set of ichnotaxobases that can be used in the identification and interpretation of trace fossils. Although only one species of sand-swimming skink was studied, the biogenic structures produced by Chalcides ocellatus provide a preliminary set of ichnotaxobases that will aid in the recognition and identification of these traces in the fossil record.

Sand-swimming skink traces are characterized by sediment homogenization, mounds and depressions, surficial and subsurficial sinuous bilobate trails, isolated and connected U- to V-shaped divots, and flame structures. Most of these structures are perpendicular to bedding with the exception of sinuous bilobate trails that are parallel to bedding. The contact between the sand-swimming traces and the surrounding sediment is sharp to gradational. The structures are passively filled as a result of gravitational collapse and lack linings, meniscate backfill, and bioglyphs.

Comparison with Other Extant Sand-Swimming Traces. Other sand-swimming reptiles, such as the sandfish (Scincus scincus), the Kenyan sand boa (Eryx colubrinus), and the Saharan sand viper (Cerastes cerastes), produce biogenic structures like those of Chalcides ocellatus in similar sediment (Young and Morain, 2003; Hembree and Hasiotis, 2007; Baumgartner et al., 2008). Studies of the mechanics of sand-swimming locomotion have primarily involved the sandfish whose method of sand swimming is nearly identical to that of $C$. 
ocellatus (Baumgartner et al., 2008; Maladen et al., 2009; Sharpe et al., 2013). These studies have shown that the burrowing behavior of $S$. scincus is similar to that of $C$. ocellatus. It can be expected then that these two sand-swimming skinks would produce very similar types of biogenic structures in loose sandy media. While these studies have not documented subsurface traces, they have shown surface structures with the same morphology as the SSBT (Baumgartner et al., 2008). Similar studies focusing on the burrowing mechanics of $C$. cerastes have shown shallow trails of a similar morphology (Young and Morain, 2003). The best documented subsurface structures are those produced by $E$. colubrinus, a medium-sized snake, capable of burrowing to depths of $20-25 \mathrm{~cm}$ in fineto coarse-grained sand (Hembree and Hasiotis, 2007). These snakes produced a greater diversity of subsurface biogenic structures than the sand skinks, including cone-shaped structures, U- to Vshaped structures, vertical to subvertical, unlined tubes, semicircular divots, and deformed and truncated beds (Hembree and Hasiotis, 2007). Of these, the semicircular divots are the most similar to the structures produced by the sand skinks, although they are significantly larger on average ( $4.0 \mathrm{~cm}$ wide and $6.0 \mathrm{~cm}$ high). The other traces produced by $E$. colubrinus were larger, more complex, and disrupted more of the sediment layers than those produced by $C$. ocellatus. In general, because of their greater size, strength, and higher levels of activity, the biogenic structures produced by E. colubrinus (Hembree and Hasiotis, 2007) are more complex and diverse than those produced by C. ocellatus.

Comparison with Eolian Trace Fossils. Numerous trace fossils have been described from modern and ancient eolian sand dunes (Ahlbrandt et al., 1978; Ekdale and Picard, 1985; Hasiotis, 2002, 2004; Loope, 2006; Ekdale et al., 2007; Loope, 2008). Most of these trace fossils, including Planolites, Palaeophycus, Skolithos, Arenicolites, Entradichnus, and Taenidium, have been attributed to the activity of burrowing arthropods such as millipedes, insects, spiders, and scorpions. These trace fossils are distinct, actively to passively filled structures that record the temporary to permanent occupation of open burrows or the active backfill of a burrow during locomotion. The morphology of these structures indicates that they were not produced by sand-swimming vertebrates. Trace fossils described by Loope (2008) from the Jurassic Entrada Sandstone, however, are indicative of sand-swimming activity. These include cone- shaped structures, U- to V-shaped divots, straight to sinuous tunnels, and deflected to truncated laminae (Loope, 2008). While the origin of these structures is not clear, they are similar to those produced by sand-swimming reptiles in laboratory experiments.

Paleoecological and Paleoenvironmental Significance. Sand-swimming traces produced by Chalcides ocellatus have a relatively low preservation potential due to the shifting nature of sand dunes. Open burrows produced by $C$. ocellatus have the greatest preservation potential in wet interdunal areas where the particles are moist and the sand is easily excavated (Loope, 2006). Given the documentation of trace fossils from known eolian deposits, in particular those of the Entrada Sandstone (Ekdale et al., 2007), however, preservation of these traces is possible. Additionally, the relative absence of body fossils from these types of sedimentary units means that trace fossils are a vital source of paleoecological data.

An increased awareness of the structures produced by desert-dwelling skinks, such as Chalcides ocellatus, not only allows for a more complete evolutionary and biographic history of skinks, but can also improve on interpretations of biodiversity. Although skinks, snakes, arthropods, and even mammals are common in modern dune fields (Albrandt et al., 1978; Kinlaw, 1999; Whitford and Kay, 1999), only a few researchers have recorded burrows and bioturbation structures in eolianites (e.g., Hasiotis, 2002, 2004; Loope, 2006; Ekdale et al., 2007; Loope, 2008). This lack of literature is likely due to the similarities in appearance between the biogenic structures produced by skinks, other desert-dwelling animals, and abiotic soft-sediment deformational features. This is problematic because skinks are important components of both healthy and recovering ecosystems (Iwamoto, 1986; Fox, 1997; Vreeland and Tietje, 2000; Norbury et al., 2009). Skinks feed primarily on insects, but also consume fruits, seeds, and vegetation (Iwamoto, 1986; Grimmond et al., 1994; Attum et al., 2007; Norbury et al., 2009; Carretero et al., 2010). Skinks are in turn consumed by other lizards, snakes, and birds (Pianka and Vitt, 2006). This places skinks in a critical position within desert food webs. The harsh conditions of arid environments make the preservation of small vertebrates such as skinks unlikely. Their absence from the fossil record of a time interval or geographic region, therefore, leads to incomplete paleoecological reconstructions and fundamentally hinders the full understanding of ancient food webs. The successful interpretation of the biogenic structures pro- 
duced by a specific group of organisms, however, allows them to be used as proxies for the presence of that organism (e.g., Bromley, 1996; Gingras et al., 2007).

Observations made during these experiments have shown that sand-swimming skinks are capable of modifying eolian sediment and play a role in pedogenesis as documented in other burrowing animals inhabiting arid environments (Hole, 1981; Kinlaw, 1999; Whitford and Kay, 1999). The burrowing activity by Chalcides ocellatus resulted in grain sorting and the overall loosening of the sediment fabric, which caused an increase in porosity and permeability. The disruption of primary sedimentary structures loosened and aerated the sand, which created flow paths for fluids and gases (e.g., Hole, 1981; Bardgett, 2005). In arid environments, these flow paths provide plant roots, micro-, and macro-fauna with a needed supply of water and oxygen (e.g., Cloudsley-Thompson, 1991; Bardgett, 2005; Schaetzl and Anderson, 2005). The loosening of dense sand through bioturbation also allows for other organisms to inhabit areas that may have once been uninhabitable due to the physical properties of the sediment (e.g., Bromley, 1996); these new organisms would, in turn, further modify the substrate and further contribute to pedogenesis. In the terrariums, the infiltration of the skink into the loose sand resulted in the downward migration of surficial sand grains, which also caused the downward movement of surficial organics (food particles, fecal material) into the sediment. Chalcides ocellatus also directly contributed organics to the surrounding sand in the form of fecal material excreted while below the surface and through the shedding of skin. In arid environments, where nutrients are scarce, the organics contributed by the skinks would provide essential nutrients to plants, microorganisms, and other macrofauna (e.g., Bardgett, 2005).

\section{CONCLUSIONS}

Through the use of modern analogs, this study has demonstrated the range of biogenic structures produced by small, rarely preserved, desert-dwelling lizards. While engaged in locomotion, escape, and resting behaviors, Chalcides ocellatus produced eight biogenic structures including temporary open burrows, mounds and depressions, homogenized sediment, surficial and subsurficial sinuous bilobate trails, flame structures, and isolated toconnected, U- to V-shaped divots. The alteration of environmental conditions including increased grain size and sediment mois- ture content led to both the exclusion of, and variations in, the structures produced by $C$. ocellatus.

Neoichnological studies are necessary for the accurate interpretation of burrowing techniques, behaviors, and tracemakers associated with trace fossils. Because continental trace fossils are understudied with respect to their marine counterparts, traces produced in continental settings are often unrecognized, under-sampled, or excluded from study. The use of modern analogs, such as skinks, in the identification of burrows produced by reptilian continental burrowers is necessary for the accurate interpretation of the paleoecology of terrestrial environments. Many of the biogenic structures produced by sand-swimming reptiles such as Chalcides ocellatus strongly resemble abiotically produced soft-sediment deformation structures and would likely be overlooked by those not trained in ichnology during paleoecological studies. Sandswimming reptiles are also important to the bioturbation of eolian deposits and their pedogenic alteration. Continued studies of macrofauna that inhabit arid, eolian systems can better inform on the rates of pedogenesis in these settings and the overall contribution of organisms to the process in what are often viewed as desolate environments.

\section{ACKNOWLEDGMENTS}

We are grateful to two anonymous reviewers whose comments and suggestions have improved this paper. We thank the National Science Foundation (EAR-0844256) and the American Chemical Society Petroleum Research Fund (49387-UNI8) for their generous support provided to Dr. Hembree to conduct this research.

\section{REFERENCES}

Ahlbrandt, T.S., Andrews, S., and Gwynne, D.T. 1978. Bioturbation in eolian deposits. Journal of Sedimentary Research, 48:839-848.

Attum, O., Eason, P., and Cobbs, G. 2007. Morphology, niche segregation, and escape tactics in a sand dune lizard community. Journal of Arid Environments, 68:564-573.

Bardgett, R. 2005. The Biology of Soil: A Community and Ecosystem Approach. Oxford University Press, Oxford.

Bartlett, R.D. and Bartlett, P.P. 1997. Lizard care from A to $Z$, (second edition). Barron's Educational Series, New York.

Baumgartner, W., Fidler, F., Weth, A., Habbecke, M., Jakob, P., Butenweg, C., and Böhme, W. 2008. Investigating the locomotion of the sandfish in desert sand using NMR-imaging. PLOS ONE, 10:1-10. 
Bertling, M., Braddy, S.J., Bromley, R.G., Demathieu, G.R., Genise, J., Mikul, R., Nielsen, J.K., Nielsen, K.S.S., Rindsberg, A.K., and Schlirf, M. 2006. Names for trace fossils: a uniform approach. Lethaia, 39:265-286.

Bromley, R.G. 1996. Trace Fossils: Biology, Taphonomy and Applications (second edition). Chapman \& Hall, London.

Carretero, M.A., Cascio, P.L., Corti, C., and Pasta, S. 2010. Sharing resources in a tiny Mediterranean island? Comparative diets of Chalcides ocellatus and Podarcis filfolensis in Lampione. Bonn Zoological Bulletin, 57:111-118.

Catena, A. and Hembree, D.I. 2014. Biogenic structures of burrowing skinks: neoichnology of Mabuya multifasciata (Squamata:Scincidae), p. 343-369. In Hembree, D.I., Platt, B.F., and Smith, J.J. (eds.), Experimental Approaches to Understanding Fossil Organisms: Lessons from the Living. Springer, Dordrecht.

Cloudsley-Thompson, J.L. 1991. Ecophysiology of Desert Arthropods and Reptiles. Springer-Verlag, Berlin, Germany.

Counts, J.W. and Hasiotis, S.T. 2009. Neoichnological experiments with masked chafer beetles (Coleoptera, Scarabaeidae); implications for backfilled continental trace fossils. Palaios, 24:74-91.

Damiani, R., Modesto, S., Yates, A., and Neveling, J. 2003. Earliest evidence of cynodont burrowing. Proceedings of the Royal Society of London Series B: Biological Sciences, 270:1747.

Datta, P. and Ray, S. 2006. Earliest lizard from the Late Triassic (Carnian) of India. Journal of Vertebrate Paleontology, 26:795-800.

Ekdale, A., Bromley, R., and Loope, D. 2007. Ichnofacies of an ancient erg: a climatically influenced trace fossil association in the Jurassic Navajo Sandstone, southern Utah, USA, p. 562-574. In Miller, W.C. (ed.), Trace Fossils: Concepts, Problems, Prospects. Elsevier, Amsterdam.

Ekdale, A.A. and Picard, M.D. 1985. Trace fossils in a Jurassic eolianite, Entrada Sandstone, Utah, U.S.A, p. 3-12. In Curran, H.A. (ed.), Biogenic Structures and Their Use In Interpreting Depositional Environments, SEPM Special Publication 35, Tulsa.

Estes, R. 1969. A scincoid lizard from the Cretaceous and Paleocene of Montana. Breviora 331:1-9.

Fox, B.J. 1997. Fauna habitat reconstruction after mining, p. 151-160. In Asher, C.J. and Bell, L.C. (eds.), Proceedings of Fauna Habitat Reconstruction After Mining Workshop. Australian Centre for Mining Environmental Research, Brisbane.

Getty, P.R., Sproule, R., Wagner, D.L., and Bush, A.W. 2013. Variation in wingless insect trace fossils: insight from neoichnology and the Pennsylvanian of Massachusetts. Palaios, 28:243-258.
Gingras, M.K., Bann, K.L., MacEachern, J.A., Waldron, J., and Pemberton, S.G. 2007. A conceptual framework for the application of trace fossils, p. 1-25. In MacEachern, J.A., Bann, K.L., Gingras, M.K., and Pemberton, S.G. (eds.), Applied Ichnology. SEPM Short Course Notes 52, Tulsa.

Gobetz, K.E. and Martin, L.D. 2006. Burrows of a gopher-like rodent, possibly Gregorymys (Geomyoidea: Geomyidae: Entoptychtinae), from the early Miocene Harrison Formation, Nebraska. Palaeogeography, Palaeoclimatology, Palaeoecology, 237:305-314.

Greenville, A.C. and Dickman, C.R. 2009. Factors affecting habitat selection in a specialist fossorial skink. Biological Journal of the Linnean Society, 97:531544.

Grimmond, N.M., Preest, M.R., and Pough, F.H. 1994. Energetic cost of feeding on different kinds of prey for the lizard Chalcides ocellatus. Functional Ecology, 8:17-21.

Groenewald, G.H., Welman, J., and MacEachern, J.A. 2001. Vertebrate burrow complexes from the Early Triassic Cynognathus Zone (Driekoppen Formation, Beaufort Group) of the Karoo Basin, South Africa. Palaios, 16:148-160.

Gupta, D.P. and Sinha, A.K. 2001. Notes on the burrows of Varanus bengalensis in and around Agra. Zoos' Print Journal, 16:651-654.

Halfen, A.F. and Hasiotis, S.T. 2010. Neoichnological study of the traces and burrowing behaviors of the western harvester ant Pogonomyrmex occidentalis (Insecta: Hymenoptera: Formicidae): paleopedogenic and paleoecological implications. Palaios, 25:703-720.

Hasiotis, S.T. 2002. Continental Trace Fossils. SEPM Short Course Notes 51, Tulsa.

Hasiotis, S.T. 2003. Complex ichnofossils of solitary and social soil organisms; understanding their evolution and roles in terrestrial paleoecosystems. Palaeogeography, Palaeoclimatology, Palaeoecology, 192:259-320.

Hasiotis, S.T. 2004. Reconnaissance of Upper Jurassic Morrison Formation ichnofossils, Rocky Mountain Region, USA: paleoenvironmental, stratigraphic, and paleoclimatic significance of terrestrial and freshwater ichnocoenoses. Sedimentary Geology, 167:177268.

Hasiotis, S.T. and Bourke, M.C. 2006. Continental trace fossils and museum exhibits: displaying organism behaviour frozen in time. Geological Curator, 8:211226.

Hembree, D.I. 2009. Neoichnology of burrowing millipedes: linking modern burrow morphology, organism behavior, and sediment properties to interpret continental ichnofossils. Palaios, 24:425-439.

Hembree, D.I. 2013. Neoichnology of the whip scorpion Mastigoproctus giganteus: complex burrows of predatory terrestrial arthropods. Palaios, 28:141-162. 
Hembree, D.I. and Hasiotis, S.T. 2006. The identification and interpretation of reptile ichnofossils in paleosols through modern studies. Journal of Sedimentary Research, 76:575-588.

Hembree, D.I. and Hasiotis, S.T. 2007. Biogenic structures produced by sand-swimming snakes: a modern analog for interpreting continental ichnofossils. Journal of Sedimentary Research, 77:389-397.

Hembree, D.I. and Hasiotis, S.T. 2008. Miocene vertebrate and invertebrate burrows defining compound paleosols in the Pawnee Creek Formation, Colorado, U.S.A. Palaeogeography, Palaeoclimatology, Palaeoecology, 270:349-365.

Hembree, D.I, Johnson, L.M., and Tenwalde, R.M. 2012. Neoichnology of the desert scorpion Hadrurus arizonensis: burrows to biogenic cross lamination. Palaentologia Electronica, 15:1.10A.

Hembree, D.I., Martin, L.D., and Hasiotis, S.T. 2004. Amphibian burrows and ephemeral ponds of the Lower Permian Speiser Shale, Kansas; evidence for seasonality in the Midcontinent. Palaeogeography, Palaeoclimatology, Palaeoecology, 203:127-152.

Hole, F.D. 1981. Effects of animals on soil. Geoderma, 25:75-112.

Iwamoto, T. 1986. Mammals, reptiles and crabs on the Krakatau Islands: their roles in the ecosystem. Ecological Research, 1:249-258.

Kinlaw, A. 1999. A review of burrowing by semi-fossorial vertebrates in arid environments. Journal of Arid Environments, 41:127-145.

Loope, D.B. 2006. Burrows dug by large vertebrates into rain-moistened Middle Jurassic sand dunes. Journal of Geology, 114:753-762.

Loope, D.B. 2008. Life beneath the surfaces of active Jurassic dunes: burrows from the Entrada Sandstone of south-central Utah. Palaios, 23:411-419.

Maladen, R.D., Ding, Y., Li, C., and Goldman, D.I. 2009. Undulatory swimming in sand: subsurface locomotion of the sandfish lizard. Science, 325:314-318.

Martin, L.D. and Bennett, D.K. 1977. The burrows of the Miocene beaver Palaeocastor, western Nebraska, USA. Palaeogeography, Palaeoclimatology, Palaeoecology, 22:173-193.

Martin, J.E., Hutchinson, M.N., Meredith, R., Case, J.A., and Pledge. N.S. 2004. The oldest genus of scincid lizard (Squamata) from the tertiary Etadunna Formation of South Australia. Journal of Herpetology, 38:180-187.

Melchor, R.N., Genise, J.F., Farina, J.L, Sanchez, M.V., Sarzetti, L., and Visconti. G. 2010. Large striated burrows from fluvial deposits of the Neogene Vinchina Formation, La Rioja, Argentina; a crab origin suggested by neoichnology and sedimentology. Palaeogeography, Palaeoclimatology, Palaeoecology, 291:400-418.

Norbury, G., Heyward, R., and Parkes, J. 2009. Skink and invertebrate abundance in relation to vegetation, rabbits and predators in a New Zealand dryland ecosystem. New Zealand Journal of Ecology, 33:24-31.
Pasteur, G. 1981. A survey of the species groups of the old-world scincid genus Chalcides. Journal of Herpetology, 15:1-16.

Pianka, E.R. and Vitt, L.J. 2006. Lizards: windows to the evolution of diversity. University of California Press, Berkeley.

Retallack, G.J., Ekdale, A.A., and Picard, M.D. 1984. Trace fossils of burrowing beetles and bees in an Oligocene paleosol, Badlands National Park, South Dakota. Journal of Paleontology, 58:571-592.

Robinson, M.D. and Seely, M.K. 1980. Physical and biotic environments of the southern Namib dune ecosystem. Journal of Arid Environments, 3:183-203.

Schaetzl, R.J. and Anderson, S. 2005. Soils: Genesis and Geomorphology. Cambridge University Press, New York.

Sharpe, S.S., Ding, Y., and Goldman, D.I. 2013. Environmental interaction influences muscle activation strategy during sand-swimming in the sandfish lizard Scincus scincus. The Journal of Experimental Biology, 216:260-274.

Shenbrot, G. and Krasnov, B. 1997. Habitat relationships of the lizard fauna in the Ramon erosion cirque, Negev Highlands (Israel). Journal of Zoology (London), 241:429-440.

Smith, J.J. and Hasiotis, S.T. 2008. Traces and burrowing behaviors of the cicada nymph Cicadetta calliope; neoichnology and paleoecological significance of extant soil-dwelling insects. Palaios, 23:503-513.

Smith, J.J., Hasiotis, S.T., Kraus, M.J., and Woody, D.T. 2008. Relationship of floodplain ichnocoenoses to paleopedology, paleohydrology, and paleoclimate in the Willwood Formation, Wyoming, during the Paleocene-Eocene thermal maximum. Palaios, 23:683699.

Smith, R.M.H. 1987. Helical burrow casts of therapsid origin from the Beaufort Group (Permian) of South Africa. Palaeogeography, Palaeoclimatology, Palaeoecology, 60:155-169.

Traeholt, C. 1995. Notes on the burrows of the water monitor lizard, Varanus salvator. Malayan Nature Journal, 49:103-112.

Vitt, L.J. and Caldwell, J.P. 2013. Herpetology: An Introductory Biology of Amphibians and Reptiles, (fourth edition). Academic Press, London.

Voorhies, M. 1975. Vertebrate burrows p. 325-350. In Frey, R.W. (ed.), The Study of Trace Fossils. Springer-Verlag, New York.

Vreeland, J.K. and Tietje, W.D. 2000. Numerical response of small vertebrates to prescribed fire in California Oak Woodland p. 100-110. In Ford, W.M., Russell, K.R., and Moorman, C.E. (eds.), The Role of Fire in Nongame Wildlife Management and Community Restoration: Traditional Uses and New Directions. Proceedings of a Special Workshop, USDA Forest Service, Northeastern Research Station, Pennsylvania. 
Wellstead, C.F. 1982. Lizards from the Lower Valentine Formation Miocene of northern Nebraska USA. Journal of Herpetology, 16:364-375.

Whitford, W.G. and Kay, F.R. 1999. Biopedturbation by mammals in desert: a review. Journal of Arid Environments, 41:203-230.
Young, B.A. and Morain, M. 2003. Vertical burrowing in the Saharan sand vipers (Cerastes). Copeia, 2003:131-137.

Vitt, L.J. and Caldwell, J.P. 2013. Herpetology: An Introductory Biology of Amphibians and Reptiles, (fourth edition). Academic Press, London. 